\title{
Comparison of the internal thoracic artery flow dissected by video endoscopy or conventional technique
}

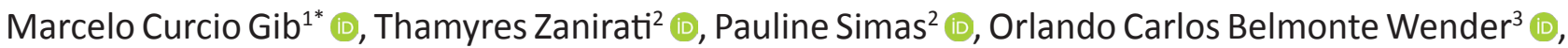 \\ Leandro Totti Cavazzola ${ }^{4}$ (D)
}

1. MD. Cardiovascular Surgery Department - Hospital de Clínicas de Porto Alegre (HCPA) - Porto Alegre (RS), Brazil.

2. Graduate student. School of Medicine - Universidade Federal do Rio Grande do Sul (UFRGS) - Porto Alegre (RS), Brazil.

3. PhD, Full Professor. Surgery Department - Hospital de Clínicas de Porto Alegre (HCPA) - Porto Alegre (RS), Brazil.

4. PhD, Associate Professor. Surgery Department - Hospital de Clínicas de Porto Alegre (HCPA) - Porto Alegre (RS), Brazil.

\begin{abstract}
Purpose: To compare the blood flow in the internal thoracic artery when dissected endoscopically in a conventional manner, in addition to develop a reliable experimental training model for the surgical team. Methods: Paired experimental study. Ten pigs were operated and had both internal thoracic arteries dissected, the right with a conventional technique and the left by video endoscopy. The main outcomes to be studied were flow, length, and time of dissection of each vessel. Results: Blood flow measurements were performed with mean heart rate of $100 \pm 16 \mathrm{bpm}$ and mean arterial pressure of $89.7 \pm 13 \mathrm{~mm} \mathrm{Hg}$. The mean blood flow of endoscopic dissection of the internal thoracic artery was $170.2 \pm 66.3 \mathrm{~mL} / \mathrm{min}$ and by direct view was $180.8 \pm 70.5(p=0.26)$. Thus, there was no statistically significant difference between the flows, showing no inferiority between the methods. Conclusions: The minimally invasive dissection of the internal thoracic artery was shown to be not inferior to the dissection by open technique in relation to the blood flow in the present experimental model. In addition, the model that we replicated was shown to be adequate for the development of the learning curve and improvement of the endoscopic abilities.
\end{abstract}

Key words: Coronary Artery Bypass. Thoracic Surgery. Mammary Arteries. Models, Animal.

*Corresponding author: mcgib99@gmail.com | (55 51)99733-0861

Received: Apr 16, 2021 | Review: Jun 15, 2021 | Accepted: July 12, 2021

Conflict of interest: Nothing to declare.

Research performed at Animal Experimentation Center, Hospital de Clínicas de Porto Alegre (HCPA), Porto Alegre (RS), Brazil. 


\section{Introduction}

The search for minimally invasive (MI) procedures, both by patients and by professionals, has been increasing nowadays. However, new technologies are usually accompanied by high cost, high learning curve, and doubtful results in the initial few cases $^{1}$. Before these facts, it is becoming increasingly important to conduct training in experimental models and on simulators in search of optimized results since the beginning of clinical experience ${ }^{2}$.

Coronary artery bypass grafting (CABG) is a wellestablished procedure in medical practice and presents excellent results ${ }^{2-4}$. The proposal of new approaches, especially the $\mathrm{MI}$ ones with less surgical trauma and a lower rate of potential complications, necessarily requires the maintenance of its current results. One of the pillars of CABG success, which has kept it competitive against stents, is the use of the left internal thoracic artery (ITA $)^{5-7}$. The aim of this study was to compare the blood flow of the left ITA, that is endoscopically dissected, to the right ITA blood flow, dissected in a conventional manner, in addition to develop a reliable experimental training model for the surgical team.

\section{Methods}

The present study was approved by the Ethics Committee on the Use of Animals of the Hospital de Clínicas de Porto Alegre (no. 130518). Ten adult Landrace pigs weighing 30 to $40 \mathrm{~kg}$ were operated on. In all animals, the two ITAs were dissected in a skeletonized fashion, the left one using video endoscopy and the right one using a median sternotomy. The sample size was calculated for paired samples with a maximum difference of $20 \%$ for no inferiority based on Demertzis' work ${ }^{8}$, with a minimum number of seven animals required. All animals were treated according to the Ethical Code for Animal Experimentation (ARRIVE guideline).

\section{Preparing the animals}

The pigs were housed for acclimatization for at least 24 hours before the procedures. They were subjected to solids fasting for 18 hours and nothing by mouth for 12 hours. Standardized preanesthetic medication consisted of ketamine hydrochloride, $15 \mathrm{mg} / \mathrm{kg}$; meperidine, $5 \mathrm{mg} / \mathrm{kg}$; and midazolam, $0.8 \mathrm{mg} / \mathrm{kg}$ intramuscularly, in the lodging and without the need for mechanical containment. Peripheral vein puncture of one of the ears and monitoring was installed for electrocardiogram and pulse oximeter. Preoxygenation was performed for 5 minutes before anesthetic induction, performed with propofol $4 \mathrm{mg} / \mathrm{kg}$ and instillation of $2 \%$ lidocaine at a dose of $0.5 \mathrm{~mL}$ for reduction of laryngospasm. Endotracheal intubation was done with tube 7 or 7.5. Maintenance of general anesthesia was performed with intravenous infusion of propofol at $0.8 \mathrm{mg} / \mathrm{kg} / \mathrm{minute}$ and fentanyl $50 \mu \mathrm{g} / \mathrm{kg}$.

The animal was initially positioned in the right lateral decubitus position with the hyperextended left upper limb exposing the axilla and the lower tip of the scapula during endoscopic video dissection of the left internal thoracic artery (LITA) after repositioning in open dorsal recumbency.

\section{Surgical instruments and positioning of the trocars}

For all experiments, the same surgical material was used. In the video that shows endoscopy, a standard 30-mm angled optics, a video camera, two 5-mm trocars, a Storz ${ }^{\circledast}$ surgery video tower, an angled dissecting forceps, an endoscopic hook attached to a monopolar electrocautery, straight traction forceps, and a 200-clamp clip were used. The experimental model developed by Demertzis ${ }^{8}$ was used for endoscopic approach. The portal of the camera was placed in the sixth intercostal space (ICS) left, 5 to $10 \mathrm{~cm}$ posterior to the posterior axillary line (PAL) and the working portals in the fifth and seventh ICS on the PAL. The left thoracic cavity was inflated by $\mathrm{CO}_{2}$, with a constant $4-8-\mathrm{mm} \mathrm{Hg}$ pressure. Once the thoracic cavity was accessed, the animals were manually ventilated until extraction of the trocars to avoid bradycardia and death (Fig. 1).

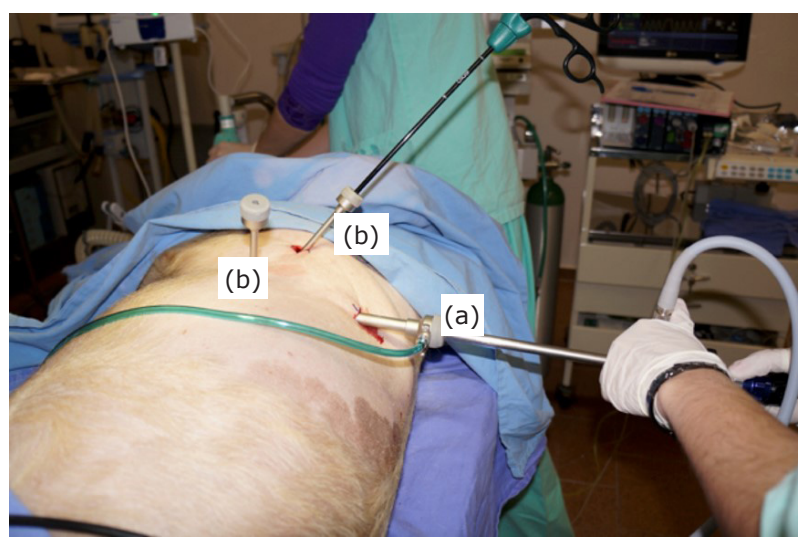

Figure 1 - Positioning of the trocars. (a) Camera port. (b) Port for the dissection and coagulation device.

\section{Anatomy of the ITA swine}

The porcine ITA is a direct branch of the subclavian artery, as in humans, and it originates at an angle of approximately $90^{\circ}$. It travels under the corresponding parietal pleura in the anterior mediastinum, being posterior to the costochondral cartilages. In its more cranial portion, the mammary was found devoid of branches and could be visualized through the endothoracic fascia. It has an approximate diameter of 5 to $6 \mathrm{~mm}$, being accompanied by larger veins with 
diameters of 6 to $12 \mathrm{~mm}$ and extremely friable walls ${ }^{8}$. From 8 to $10 \mathrm{~cm}$ of its origin, a thick muscular layer covers the ITA with approximately 1 to $2 \mathrm{~cm}$ until its bifurcation in the final portion of the thorax a few centimeters before penetrating the diaphragm. In this portion, the ITA emits several branches that leave mainly the anterior surface of the vessel and some of them of great caliber.

\section{ITA endoscopic video approach}

Using dissecting forceps, the ITA was approached by creating a window at the middle level of its more cranial portion. The artery was dissected initially in its cranial portion in which it presents, in most of the times, devoid of branches. Releasing the entire muscle portion completes the dissection. In this follow-up, the entire extension was first exposed, and the obliteration of each of its branches was performed-with clipping and/or cauterization according to the caliber of the branch.

\section{Open approach of ITA}

In the supine position, a longitudinal thoracic incision was made on the midline, and total median sternotomy was performed. The anterior mediastinum was approached with the use of Finochietto retractor. Under direct view, the right ITA was skeletonized from its cranial portion to its distal bifurcation, using monopolar electrocautery, anatomical forceps, Metzenbaun and Potts scissors, as well as clipping or cauterization of its branches, following the criteria used on the contralateral side.

\section{Blood flow analysis and measurement of ITA length}

At the end of complete dissection of both mammary arteries, intravenous heparin ( $1 \mathrm{mg} / \mathrm{kg}$ ) was administered. The distal portion of each artery was clipped near the bifurcation and externalized medially on the pericardium. Each ITA was completely wrapped with gauze, and $10 \mathrm{~mL}$ of papaverine topical solution was instilled. A direct puncture in ascending aorta artery was performed to measure the mean arterial pressure (MAP). After another 5 minutes, the length of ITA was measured using a ruler, from its origin to the distal clip. A complete transverse arteriotomy was then performed at its distal portion to remove the clip, and blood flow was collected for 30 seconds in a vial and measured and multiplied by 2 to avoid hemodynamic deterioration. Saline solution was used to obtain a MAP and heart rate (HR) similar to the initial ones followed by measuring the flow in the contralateral ITA.

\section{Definition of surgical times}

Zero time (ZT) was defined as the time when the animal was anesthetized and positioned for the procedure. The time interval between the beginning of the endoscopic dissection and the removal of the trocars was defined as endoscopic time (ET). Open time (OT) was defined as the time when cutaneous incision was started at the right ITA clipping.

\section{Statistical analysis}

t-Tests for paired samples and Fisher's exact test for categorical variables were used. Statistical analysis was performed by statistical program (StatGraphics Plus 2.1, Statistical Graphics Corporation, United States), consisting of comparative tests of the means (Student's t-test) and analysis of variance (ANOVA). The results were represented as mean \pm standard error of the mean, with a level of statistical significance defined for $p<0.05$.

\section{Results}

The same surgeon and team performed all surgeries. Ten pigs were operated on, and all mammary arteries were successfully dissected. The mean weight of the animals was $34.2 \pm 2.21 \mathrm{~kg}$ (Table 1). Blood flow measurements were performed with an average HR of $100 \pm 16 \mathrm{bpm}$, and MAP of $89.7 \pm 13 \mathrm{~mm} \mathrm{Hg}$. The mean of the ITA blood flow was similar between the two groups. The mean blood flow in the endoscopic dissection was $170.2 \pm 66.3 \mathrm{~mL} / \mathrm{min}$ and by direct view was $180.8 \pm 70.5 \mathrm{~mL} / \mathrm{min}$ ( $p=0.260 ; 95 \%$ confidence interval-IC95\%-30.5-9.23) (Fig. 2). Thus, there was no statistically significant difference between the flows.

Following the findings already described in the literature, the time taken for the endoscopic procedure was longer than that of the direct view procedure with a median of 57.5 (49.5-77.5 $\mathrm{min}$ ) and $43.5 \mathrm{~min}(39.75-48.5 \mathrm{~min})$, respectively, with statistical difference $(p=0.008)$ (Fig. 3 ).

Table 1 - Demographic data of animals.

\begin{tabular}{cccc}
\hline Animal & Weight $(\mathbf{k g})$ & MAP $(\mathbf{m m H g})$ & HR (bpm) \\
\hline $\mathbf{1}$ & 34.3 & 90 & 98 \\
$\mathbf{2}$ & 34.6 & 86 & 92 \\
$\mathbf{3}$ & 34.2 & 80 & 85 \\
$\mathbf{4}$ & 34 & 110 & 100 \\
$\mathbf{5}$ & 31.2 & 95 & 87 \\
$\mathbf{6}$ & 31 & 93 & 87 \\
$\mathbf{7}$ & 33.2 & 60 & 91 \\
$\mathbf{8}$ & 38.3 & 90 & 120 \\
$\mathbf{9}$ & 36.7 & 97 & 135 \\
$\mathbf{1 0}$ & 35.1 & 96 & 106 \\
\hline
\end{tabular}

MAP: main arterial pressure; HR: heart rate. 


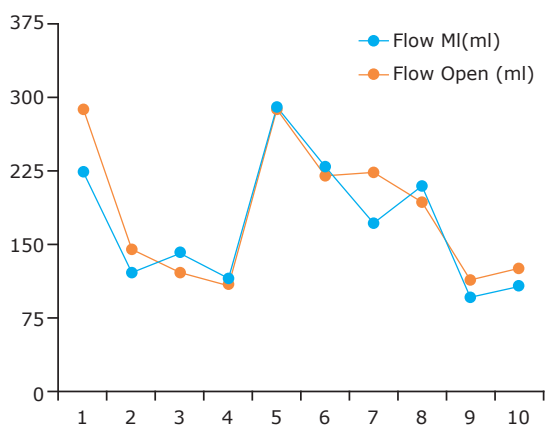

Mammary flow in milliliters per minute in each of the 10 pigs

Figure 2 - Mammary flow in milliliters per minute in each of the 10 studied pigs through free bleeding.

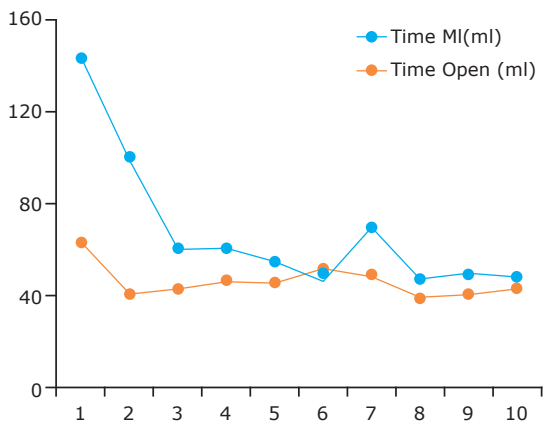

Time to complete each dissection in minutes

Figure 3-Comparison of the dissection time of the mammary arteries, in minutes, by endoscopic and direct vision.

A learning curve with a significant improvement in the time after case 3 was observed. An oscillation occurred in case 7 , which presented a large inflammatory process and parietal pleural adhesions, requiring a longer time for the release of the cavity and the artery, which had repercussion on the value of the endoscopic blood flow. The length of the open-dissected mammary was significantly higher, $13.73 \pm 1.37$ in the endoscopic group and $14.22 \pm 1.58$ in the open IC95\% (-0.87--0.10) ( $p=0.018)$ (Fig. 4).

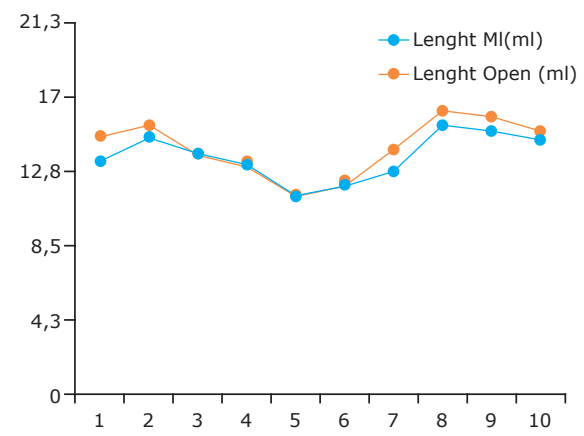

Length of mammary (centimeters) in each of 10 pigs

Figure 4 - Comparison of internal thoracic artery length in centimeters after preparation with papaverine solution and warm saline solution.
There were three cases of branch dissection without loss of ITA flow, one in the open technique and two in the endoscopic one, all related to the placement of the metal clips. In this series, no cases of major bleeding or transoperative deaths were observed. In three cases, cardiac arrhythmias were observed during the blood flow measurement phase, with two ventricular fibrillations requiring internal electrical cardioversion with $10 \mathrm{~J}$ and one sustained ventricular tachycardia with spontaneous reversal. The final cost of the project was US\$2,117.65 (less than US\$250 per case). This final computed cost is only for the pigs and disposable materials used in the experiment, and does not include facility or housing expenditures.

\section{Discussion}

Myocardial revascularization (CABG) is one of the most frequent surgeries performed worldwide, and in the last three decades many advances have occurred. One of the fundamental pillars of the long-term success of this procedure is the choice of grafts ${ }^{9}$. The LITA is the major determinant of a good late outcome in $\mathrm{CABG}^{10}$. It is believed that this occurs because of the structure and function of the artery, in which the middle tunica receives blood flow from the lumen of the vessel itself $f^{11,12}$. The literature states that the mean patency rate of LITA at 10 and 15 years to be 93 and $88 \%$, respectively, whereas saphenous vein patency in these same periods to be 71 and $32 \% 3,4,6,10$. This superiority in graft patency results in an increase in survival over 10 years (LITA for anterior descending artery-ADA $82.6 \%$, saphenous for ADA 71\%) with a lower incidence of myocardial infarction, hospitalization for cardiac events or reoperation ${ }^{13-15}$.

The current interest in being able to perform the procedures through increasingly smaller incisions has led to the introduction of assisted video thoracoscopy techniques, the field of cardiac surgery being the largest exponent of robotic surgery. MI surgery has proven to be beneficial to both medical and economical aspects and is already classified as a gold standard for many procedures in various specialties ${ }^{16,17}$.

Technological advances have brought new surgical instruments to the armamentarium of cardiac surgery, allowing the accelerated development of $\mathrm{MI}$ techniques ${ }^{15}$. Ideally, MI myocardial revascularization should attempt to include the following aspects: small access, with minimal rib spacing, performed without the use of extracorporeal circulation, offering complete revascularization, and if possible, arterial grafts ${ }^{16,18,19}$.

There is a clear learning curve to be followed by every surgeon who engages with $\mathrm{Ml}$ techniques. This step varies for each procedure, causing fear in many professionals not to 
use a well-established technique and good results if risking a new approach ${ }^{1}$. Virtual reality and video training are used in a preclinical phase to reduce training time in the operating room ${ }^{20}$. Simulation offers significant benefits to surgical trainees by allowing for repeated practice of a specific skill set in a safe and controlled environment ${ }^{21}$. Experimental models can help surgeons become familiar with the procedure, consequently speeding up their learning process.

Endoscopic CABG has been developed for the last two decades by several large cardiac surgery centers. The incorporation of robotic technology allowed the progression of this procedure, making it reality ${ }^{1}$. Because it is an extremely complex and expensive procedure, robotic CABG (TECAB) requires a specific and gradual training of surgeons to master this approach and a highly powerful medical center for such a procedure. Valdis ${ }^{2}$ performed the first randomized clinical trial to compare the three different training modes for robotic cardiac surgery, and the found results highlight the beneficial use of wet labs in robotic simulation training, suggesting their use whenever possible for a fast and safe acquisition of robotic skills ${ }^{2}$.

A key step in the development TECAB is the dissection of ITA. The preparation of the ITA under direct vision through a small incision is feasible but requires significant rib spacing and an expressive distortion of the anterior thoracic wall ${ }^{8}$. In this scenario, endoscopic video dissection of the ITA appears as a prerequisite in performing a TECAB ${ }^{19}$. Endoscopic manipulation of the ITA in a closed thoracic cavity is a technically delicate procedure and is associated with a substantial risk of vessel damage ${ }^{8}$. There are limited possibilities of controlling heavy bleeding of the mammary or its branches. Consistent surgical skills are needed to reduce the number of ITA injuries or urgency conversions for the open technique.

The comparison of the ITA flow in our study showed no inferiority when compared with the traditional method encouraging us to move forward in this line of treatment. The experimental model used allows direct comparison of the two techniques regarding the blood flow in each animal, allowing the observation of errors, correctness, and repair of the technique case by case. The results suggest that we can reach outcomes similar to those of conventional surgery with the use of video endoscopy and allow the widespread use of hybrid procedures, besides training surgeons willing to initiate the use of MI techniques.

The assisted video procedure is technically demanding, even for surgeons with good thoracoscopic skills. The learning of these skills can be protracted, especially for those who are not familiar with video surgery in their everyday lives. An experimental training model can help surgeons become familiar with the procedure and thus speed up their learning process. In our study, this curve was more significant in the first three cases and reached stability between the fourth case and the tenth case. A significant difference between the times of dissection was observed and may be explained by the long experience in performing open dissections. However, a trend in time reduction may already be noted in Fig. 3. Likewise, it is believed that the graft length has been shown to be longer in the open mode, which may be because of the considerable caution the surgeon preferred in proceeding with the dissection in its caudal portion, under which the muscle layer is thicker, and the diameter of the vessel is finer.

Studies have shown that swine models are ideal for in-vivo training of Ml surgical techniques ${ }^{2,18,22-24}$. A standardized experimental model in pigs represents a useful tool for the training of surgeons to develop their skills. The model developed by Jiga et al. ${ }^{22}$ seems to have a rapid learning curve, requiring minimal experience in laparoscopic surgery, serving as a practical preparation for performing more complex procedures, such as dissection of the ITA for MI cardiac surgery. However, this model has the disadvantage that the dissection of the ITA occurs only in the proximal third, a relatively small portion (mean of $3.2 \mathrm{~cm}$ in length), and is devoid of branches in swine.

A great advantage of the model adapted in the present study is the low cost associated with the simplicity of the surgical material required for the procedures ${ }^{8}$. This low cost also seems to serve as an inclusion factor for mid-sized services or from less developed countries to enter the world of $\mathrm{MI}$ procedures. The importance of the development of experimental models for the treatment of ischemic heart disease is growing, even as maintaining similar results to those already obtained by conventional surgery.

Concerning the limitations of the present study, it is important to consider some issues. There was a significant variation in the ease of access to the ITA region, shown to be proportional to the animal size. Pigs weighing close to $40 \mathrm{~kg}$ allowed a better manipulation of the instruments, as against in animals with less than $35 \mathrm{~kg}$. The fragility of the ITA wall is a factor that must be observed, considering its dissection is extremely easy. Finally, the experience of the surgeon regarding the direct view surgical technique should be emphasized, which may have been biased when compared with surgical times and length.

Minimally invasive techniques are the future of cardiovascular surgical procedures. The importance of the development of training models that allow a broad improvement of the professionals in a financially accessible manner is increasing. Our study intends to stimulate cardiovascular surgeons to use new therapies for the treatment of ischemic heart disease with results similar to those already obtained by conventional surgery. 


\section{Conclusions}

The MI dissection of the ITA has shown to be not inferior to the dissection by open technique in the present experimental model. The model has shown to be adequate to develop and improve endoscopic skills.

\section{Authors' contribution}

Design of the study: Cavazzola LT, Wender OCB and Gib MC; Technical procedures: Gib MC, Cavazzola LT, Zanirati T and Simas P; Manuscript writing: Gib MC, Cavazzola LT, Zanirati T and Simas P; Critical revision: Cavazzola LT and Wender OCB.

\section{Data availability statement}

Data will be available upon request.

\section{Funding}

Funds of the Research and Events Incentive Fund, Hospital de Clínicas de Porto Alegre.

Grant n 130518

\section{Acknowledgments}

To Marta J. Cioato, Coordinator of the HCPA Animal Experimentation Center (CEA HCPA), to all CEA HCPA employees and collaborators, especially the veterinarians who were with us during all procedures, working hard to maintain the physiological condition of the pigs.

\section{References}

1. Bonatti J, Schachner T, Bernecker O, Chevtchik O, Bonaros N, Ott $H$, Friedrich G, Weidinger F, Laufer G. Robotic totally endoscopic coronary artery bypass: program development and learning curve issues. J Thorac Cardiovasc Surg. 2004;127(2):504-10. https://doi.org/10.1016/j.jtcvs.2003.09.005

2. Valdis M, Chu MW, Schlachta C, Kiaii B. Evaluation of robotic cardiac surgery simulation training: $A$ randomized controlled trial. J Thorac Cardiovasc Surg. 2016;151(6):1498-505e2. https://doi.org/10.1016/j. jtcvs.2016.02.016.

3. Goldman S, Sethi GK, Holman W, Thai H, McFalls E, Ward HB, Kelly RF, Rhenman B, Tobler GH, Baken FG, Huh J, Soltero $E$, Moursi M, Haime M, Crittenden M, Kasirajan V, Ratliff $M$, Pett S, Irimpen A, Gunnar W, Thomas D, Fremes $S$, Moritz T, Reda D, Harrinson L, Wagner TH, Wang $Y$, Planting L, Miller M, Rodriguez Y, Juneman E, Morrison D, Pierce MK, Kreamer S, Shih MC, Lee K. Radial artery grafts vs saphenous vein grafts in coronary artery bypass surgery: a randomized trial. JAMA. 2011;305(2):167-74. https://doi. org/10.1001/jama.2010.1976
4. Goldman S, Zadina K, Moritz T, Ovitt T, Sethi G, Copeland JG, Thottapurathu L, Krasnicka B, Ellis N, Anderson RJ, Henderson W. Long-term patency of saphenous vein and left internal mammary artery grafts after coronary artery bypass surgery: results from a Department of Veterans Affairs Cooperative Study. J Am Coll Cardiol. 2004;44(11):2149-56. https://doi.org/10.1016/j.jacc.2004.08.064

5. Tatoulis J, Buxton BF, Fuller JA. Patencies of 2127 arterial to coronary conduits over 15years. Ann ThoracSurg. 2004;77(1):93101. https://doi.org/10.1016/s0003-4975(03)01331-6

6. Hlatky MA, Boothroyd DB, Reitz BA, Shilane DA, Baker LC, Go AS. Adoption and effectiveness of internal mammary artery grafting in coronary artery bypass surgery among Medicare beneficiaries. J Am Coll Cardiol. 2014;63(1):339. https://doi.org/10.1016/j.jacc.2013.08.1632

7. Lytle BW, Loop FD, Cosgrove DM, Taylor PC, Goormastic M, Peper W, Gil CC, Golding LA, Stewart RW. Fifteen hundred coronary reoperations. Results and determinants of early and late survival. J Thorac Cardiovasc Surg. 1987;93(6):847-59

8. Demertzis SD, Laschke MW, Siclari FP, Menger MD. Non-robotic thoracoscopic internal mammary artery preparation in the pig. A training model. Interact Cardiovasc Thorac Surg. 2008;7(4):556-9. https://doi. org/10.1510/icvts.2008.176636

9. Locker C, Schaff HV, Daly RC, Bell MR, Frye RL, Stulak JM, Said SM, Derani JA, Joyce LD, Greason KL, Pochettino A, Li Z, Lennon RJ, Lerman A. Multiarterial grafts improve the rate of early major adverse cardiac and cerebrovascular events in patients undergoing coronary revascularization: analysis of 12615 patients with multivessel disease. Eur J Cardiothorac Surg. 2017;52(4):746-52. https://doi. org/10.1093/ejcts/ezx171

10. Johnston DR. Long-term results of multiple arterial bypass conduits. Curr Opin Cardiol. 2014;29(6):542-6. https://doi. org/10.1097/HCO.0000000000000116

11. Edwards FH, Clark RE, Schwartz M. Impact of internal mammaryartery conduits on operative mortality in coronary revascularization. Ann Thorac Surg. 1994;57(1):27-32. https://doi.org/10.1016/0003-4975(94)90360-3

12. Loop FD, Lytle BW, Cosgrove DM, Golding LA, Taylor PC, Stewart RW. Free (aorta-coronary) internal mammary artery graft. Late results. J Thorac Cardiovasc Surg. 1986;92(5):827-31.

13. Loop FD, Lytle BW, Cosgrove DM, Stewart RW, Goormastic M, Williams GW, Golding LA, Gill CC, Taylor PC, Sheldon WC. Influence of the internal-mammaryartery graft on 10-year survival and other cardiac events. N Engl J Med. 1986;314(1):1-6. https://doi.org/10.1056/ NEJM198601023140101

14. Desai ND, Naylor CD, Kiss A, Cohen EA, Feder-Elituv R, Miwa S, Radhakrishnan S, Dubbin J, Schwartz L, Fremes SE. Impact of patient and target-vessel characteristics on arterial and venous bypass graft patency: insight from a randomized trial. Circulation. 2007;115(6):684-91. https:// doi.org/10.1161/CIRCULATIONAHA.105.567495 
15. Cheng A, Slaughter MS. How I choose conduits and configure grafts for my patients-rationales and practices. Ann Cardiothorac Surg. 2013;2(4):527-32. https://doi. org/10.3978/j.issn.2225-319X.2013.07.17

16. Rodriguez $M$, Ruel $M$. Minimally invasive multivessel coronary surgery and hybrid coronary revascularization: can we routinely achieve less invasive coronary surgery? Methodist Debakey Cardiovasc J. 2016;12(1):14-9. https:// doi.org/10.14797/mdcj-12-1-14

17. Zhu P, Zhou P, Sun Y, Guo Y, Mai M, Zheng S. Hybrid coronary revascularization versus coronary artery bypass grafting for multivessel coronary artery disease: systematic review and meta-analysis. J Cardiothorac Surg. 2015;10:63. https:// doi.org/10.1186/s13019-015-0262-5

18. Ducko CT, Stephenson ER Jr., Sankholkar S, Damiano RJ, Jr. Robotically-assisted coronary artery bypass surgery: moving toward a completely endoscopic procedure. Heart Surg Forum. 1999;2(1):29-37

19. Loulmet D, Carpentier A, d'Attellis N, Berrebi A, Cardon C, Ponzio O, Aupecle B, Relland JY. Endoscopic coronary artery bypass grafting with the aid of robotic assisted instruments. J Thorac Cardiovasc Surg. 1999;118(1):4-10. https://doi.org/10.1016/S0022-5223(99)70133-9
20. Gurusamy KS, Aggarwal R, Palanivelu L, Davidson BR. Virtual reality training for surgical trainees in laparoscopic surgery. Cochrane Database Syst Rev. 2009(1):CD006575. https://doi.org/10.1002/14651858.CD006575.pub2

21. Kumar A, Smith R, Patel VR. Current status of robotic simulators in acquisition of robotic surgical skills. Curr Opin Urol. 2015;25(2):168-74. https://doi.org/10.1097/ MOU.0000000000000137

22. Jiga LP, Cristian H, Blidisel A, Sandra F, Nistor A, Hoinoiu $B$, Dornean V, lonac M. Thoracoscopic approach of the internal mammary artery (IMA): a training model in pigs. Microsurgery. 2008;28(5):375-9. https://doi. org/10.1002/micr.20499

23. Bolotin G, Scott WW, Jr., Austin TC, Charland PJ, Kypson AP, Nifong LW, Salleng K, Chitwood Jr WR. Robotic skeletonizing of the internal thoracic artery: is it safe? Ann Thorac Surg. 2004;77(4):1262-5. https://doi. org/10.1016/j.athoracsur.2003.09.074

24. Shimizu Y, Watanabe G, Tomita S, Matsumoto I, lino K. A novel technique for harvesting the internal thoracic artery: linear harvesting technique using an ultrasonic surgical aspirator. Interact Cardiovasc Thorac Surg. 2011;12(6):9981001. https://doi.org/10.1510/icvts.2010.264929 